\title{
ZULU ORAL NARRATIVE DEVELOPMENT FROM A SPEECH AND GESTURE PERSPECTIVE
}

Ramona Kunene-Nicolas

The University of the Witwatersrand

Literature on child language development usually focuses mainly on early language acquisition (0 - 4 years) and on non-Bantu languages. This article focuses on 1) late language development and 2) the complete language communicative process, which includes non-verbal clues in first language Zulu oral narratives. This study brings evidence that shows pragmatic discursive ability develops with age and that spontaneous co-speech gesture develops in parallel. In a controlled language production task, oral narratives were elicited from three child cohorts (6 years, 9 years and 12 years) and one adult group. Results show a gradual increase of discursive ability in both speech and co-speech gesture. We also present quantifiable evidence that 12-year-old Zulu children are not yet as competent in complex discourse as adults, in line with current literature on late language development of other Asian and European languages. These findings are relevant for understanding how oral and writing skills develop in informal and formal learning environments.

Keywords: Oral Narratives, Co-speech Gesture, Bantu Language, Zulu, Discourse, Late Language Development.

\section{INTRODUCTION}

This paper presents the first study of the development of narrative abilities of Zulu from a multimodal perspective. It is also the first study that looks at narrative production from both speech (linguistic) and gesture (non-verbal) perspective of a Bantu language. Literature on the development of Bantu languages, within the South African context, mostly focuses on a particular construction, such as, the passive construction (Demuth, 1992) or the acquisition of the noun class system (Suzman, 1991) and not discourse. Most studies investigate on early language acquisition (0 - 4 years) and there is a dearth of information on what happens to Bantu-speaking children during late language acquisition $(5-16$ years). Whilst current studies bring important findings on language acquisition, there is the rather narrow focus on phonological, syntactic, lexical, and semantic aspects at the word or sentential level and little focus on higher language processes such as conversational abilities, discourse and the multimodal interaction of different aspects of communication (Gullberg, de Bot \& Volterra, 2010). The multimodal nature (linguistic and gesture) of speech is a scientific domain gaining in recognition in several fields including, psycholinguistics, speech therapy, psychology, to name a few. Empirical evidence shows that gestures are visual-spatial phenomena intrinsically linked to language and speech (Kendon, 2004; McNeill, 1992, 2005; Beattie \& Shovelton, 2006). Several 
researchers have shown that gesture and speech form a tightly integrated system during language production and comprehension (McNeill 1992, 2005; GoldinMeadow \& Butcher, 2003; Kita \& Özyürek, 2003).

In the current study, we investigate the effect of language and age on children's speech and gesture production during a narrative elicitation task. Literature on the communicative behaviour of young children from a multimodal perspective is steadily growing, for instance, for French (Colletta, 2004; Colletta et al., 2015; Guidetti, 2002, for Italian (Graziano, 2009) to name a few. However, little is known about how multimodal speech develops after two years. Guidetti (2002) demonstrates that children start with emblems or quotable gestures such as the pointing gesture (deictic gesture) or the waving of a hand in a greeting. These gestures continue after the pre-linguistic period and interplay with the child's first utterances during the oneto two-word transition period (Capirci et al., 1996, 2002; Goldin-Meadow \& Butcher, 2003). From the child's third year, their gestural repertoire evolves to include different types of gestures over and above deictic gestures (Guidetti, 2002; Colletta, 2004), and they start to include other types of gestures such as (terminology from McNeill, 1992; Kendon, 2004):

1. Conventional gestures/ quotable gesture/ emblems (e.g., the 'sharp' gesture in South Africa, which has the hand closed with the thumb pointing upwards) are gestures that are understood within a particular community and sometimes, in the absence of speech.

2. Iconic gestures are gestures that resemble concrete objects or actions (e.g., forming a spherical shape to represent an egg).

3. Metaphoric gestures or representational gestures represent abstract concepts (e.g., a finger making repetitive linear movements to signal that the duration is long).

4. Gestures of discourse cohesion or pragmatic gestures, gestures that accompany cohesive cues such as connectives or illocutionary speech acts (e.g., two fingers visually drawing inverted commas to emphasise something).

These various types of gestures develop in parallel to speech development.

\section{ORAL NARRATIVE DEVELOPMENT}

The ability to produce coherent narrative texts develops in parallel to the increase of cognitive and linguistic skills of the child (Berman \& Slobin, 1994; Berman, 2004, 2008). The construction of an original story, in speech or in writing, is a complex and demanding process, involving formulating, planning and organising ideas, beyond the sentence level as well as self-regulation and pre-suppositional capacities, i.e. pragmatic skills (Hadley \& Schuele, 1998; Moonsamy, Jordaan \& Greenkop, 2009). To narrate requires the integration of several competencies and it presents, in addition to linguistic difficulties, a generally greater cognitive challenge of developing the contents in hierarchically ordered sequential structures. Evidence from empirical research supports the use of narratives as an effective platform for the performance of oral language skills because storytelling requires more complex language than that needed for daily conversations (Stadler and Ward, 2005). Narrative skills are very important in literacy as classroom instruction is normally presented as connected discourse (Adler, 2012). In speech therapy, narratives are used as a diagnostic tool to identify speech disorders (Norbury \& Bishop, 2003) and learners that may be at risk Per Linguam 2015 31(3):1-18 http://dx.doi.org/10.5785/31-3-560 
for reading problems (McCabe and Rollins, 1994). Other researchers (Hickmann, 2003; Berman \& Slobin, 1994; Bruner, 1991; Vygotsky, 1962) show the links between narratives and conceptual and cognitive development.

Consequently, narratives are useful to observe the development of language skills. Older children start to verbalise chained sequences of actions as they appear in the event or story they tell, yet they merely juxtapose facts until the age of $9-10$ years (Fayol, 1997). Considering the pragmatic heterogeneity of oral narratives (Labov, 1978; Laforest \& Vincent, 1996; McNeill, 1992) telling a story also involves backtracking in the event frame. For instance, when retelling a complex event, the narrator may not follow the order of events as they originally appeared, and may have to mark every break they make in the narrative thread during narration. Besides, narrating can be viewed as complex discourse behaviour involving 'metadiscourse' in the form of personal commentary (explicitation, explanation, and evaluation in the form of personal judgment (Labov, 1978; Laforest \& Vincent, 1996; Peterson \& McCabe, 1991). In this way, a narrator can incorporate his/her own experience shaped by his/her social and cultural experience as well as other factors such as literacy.

By the age of 9 years, the child has not yet fully acquired the complexity of discourse such as organising text on several levels: narrative, meta-narrative and para-narrative levels (McNeill, 1992; Colletta, 2004). The narrative level refers to a 'true' account of events; the meta-narrative level refers to structuring the story during its narration by the speaker and the para-narrative level refers to the inclusion of personal experience and references linking the narrator and their narrative. The path to becoming a proficient speaker of any given language is a long developmental trajectory (Berman, 2004; Berman, 2008; Berman \& Slobin, 1994; Hickmann, 2003) meaning that even children in primary school have not yet completed the process from emergence to mastery.

Several researchers have shown that the ability to use communicative gestures increases in production as the child grows older (Guidetti, 2002; Colletta, 2004; Colletta et al., 2015).

This study is directly linked to a larger project (Colletta et al, 2015), which investigated the developmental trajectory of oral narrative behaviour of French, Italian and American English speakers. Findings from the above study show that the narrative ability develops with age (Colletta, Pellenq and Guidetti, 2010, ReigAlamillo, Colletta and Guidetti, 2013) and that by the age of 10 years, a child is still far from giving a narrative production as rich and complex as an adult. This study looked at two children cohorts (6 years and 10 years) and adults of the above-listed languages.

In our present study, we look at this range for a comparative analysis, but we also look at an older age group (11 to 12 years) to further investigate the developmental trajectory during the pre-adolescent period. So, in order to test the nature and the strength of developmental changes already reported on narrative development, we include a different language family, namely Zulu, which has a different linguistic structure from the three languages listed above. 


\section{THE PRESENT STUDY}

The aim of this study is to elicit oral narrative behaviour from Zulu and French speakers in order to investigate the developmental changes from a cross-linguistic point of view in Zulu. To address the hypothesis that narrative ability develops with age and is affected by linguistic and cultural factors, four age groups are selected to participate in the study. There are three children groups, i.e. five-year-olds, ten-yearolds and twelve-year olds. Adults are also included as they represent the target language (control). Investigations of co-speech gestures generally use video clips (cartoons, movies, short, animated scenes) to elicit multimodal narrative data.

In terms of predictions, we expect that a) the older the Zulu-speaking child is, the longer and more complex their oral narrative is in speech, b) the older the Zulu child the better they will be at deploying gestural resources in their narrative, and c) at the age of 11 years, the Zulu child is still not able to produce a narrative production like an adult.

\section{METHOD}

\section{PARTICIPANTS}

Forty-six (46) mother tongue, Zulu-speaking children and adults participated in this study. Participant cohorts were chosen on the premise that the youngest participants have just begun formal schooling, the middle group has been in a formal school environment for three years and the last child cohort was chosen on the basis of being the last year of primary school at the time of data collection. The participants were then split into four cohorts; 5- to 6-year-olds (mean age 5.7 years), 9- to 10-year-olds (mean age 9.5 years), 11- to 12-year-olds (mean age 11.7 years) and adults (mean age 23.4 years). Each cohort had an equal gender split.

All adults were university students from the University of Zululand. They were recorded in an allocated room in one of the dormitories. The children participants were selected from a semi-rural school in the Mthunzini, KwaZulu-Natal region. All the children were interviewed individually in their school classroom after school activities. The children participants were selected with the aid of their class teachers.

\section{PROCEDURE}

The participants were asked to watch a video extract $(2 \mathrm{~m} 47 \mathrm{~s})$ of a wordless cartoon, extracted from the cartoon TV series Tom \& Jerry, and to retell the story. The participants' narratives were videotaped for later analysis. The procedure consisted of filming the children in a semi-school environment; at school but out of the classroom environment. Participants were tested individually in a quiet area. Adults were interviewed in a student room at the University. The protocol was suitable for all age groups including adults. 


\section{CODING}

The data transcription and annotation was done on the linguistic annotation tool $E L A N^{1}$ software (see Fig. 1). An annotation scheme specially designed for this type of study (Colletta et al., 2009) was used. The annotation scheme provides information on lexical items, syntax, discourse, co-speech gesture, etc. Coding included the annotation of speech and gesture.

\section{Figure 1: Image of Annotation File on ELAN}

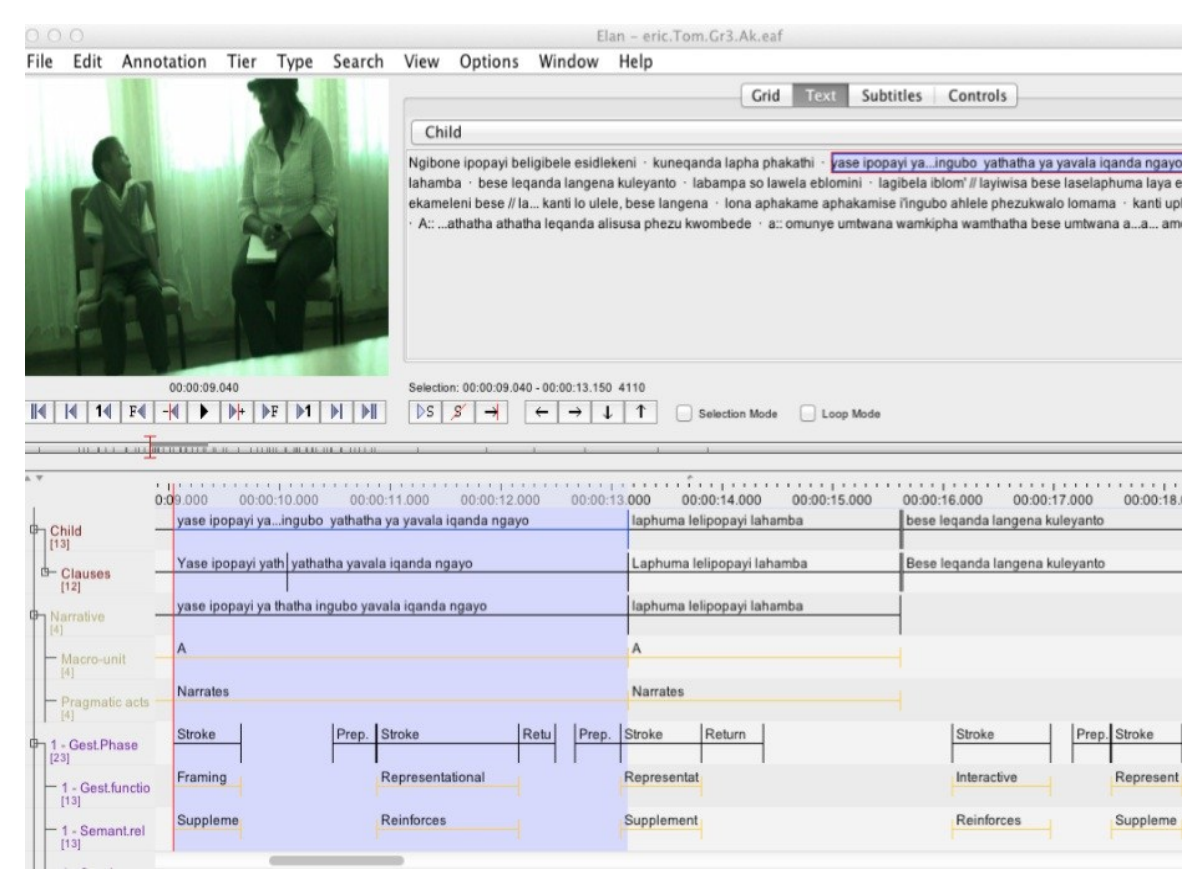

\section{SPEECH CODING}

In order to assess the informational quantity of the oral narratives produced, the verbal stream was segmented into different linguistic units such as speech turns, clauses, words, syntactic structure, and pragmatic functions. In this study we present some of the linguistic units analysed.

Language complexity: Speech was further segmented into clauses (a predicate matched by one or several arguments) as a linguistic processing unit can roughly be approximated by a clause (Garrett, 1982; Levelt, 1989; Kita \& Özyürek, 2003). The number of clauses in an account also provides a good indication of its informational quantity that is likely to grow with age.

Pragmatic acts: Pragmatic heterogeneity (Labov, 1978) and complex discourse structure develop with age (Colletta, 2004; Colletta et al., 2010). The narrative does not repose on only one level but navigates between the narrative, meta-narrative as well as the para-narrative levels (McNeill, 1992). To study how age affects pragmatic

$1 \mathrm{http}: / /$ www.lat-mpi.eu/tools/elan/

Per Linguam 2015 31(3):1-18 
and discourse dimensions of the narrative activity, we categorised each clause as expressing the part or whole of a speech act. The categories were narrating, explaining, interpreting or commenting (Colletta et al., 2009: 58).

1. Narration: When the speaker tells the event as it happens in cartoon (for instance, "There was a mother bird in the nest").

2. Explanation: When the speaker adds precision of a causal nature to the narrated event (for instance, "The mother bird left the nest because it was hungry").

3. Interpretation: When the speaker presents an inference or an interpretation concerning the situation or the intentions of the characters (for instance, "It looked at the time and realised it's time to fetch food").

4. Commentary: When the speaker presents information that is neither explicit nor implicit of the course of the events but presents a 'meta-narrative' comment relating to a character, an action or any aspect of the story, or a 'para-narrative' comment relating to the action of telling the story-judgement, personal appreciation (for instance, "It is a crazy bird" or "It made me laugh when the little bird destroyed everything in the house").

\section{GESTURE CODING}

For gesture coding, only the bodily movements maintaining a relation to speech (cospeech gesture) were annotated. Coders identified a gesture then attributed a function to it. Gesture function was grouped into two groups; representational gestures and non-representational gestures (coding manual ${ }^{2}$ (p.25-26), Colletta et al., 2009). The coders had to choose between:

\section{Representational gestures}

Hand or facial gesture, associated or not to other parts of the body, which represents an object or a property of this object, a place, a trajectory, an action, a character or an attitude (e.g. two hands drawing the form of the referent; hand or head gesture pointing to a spot that locates a virtual character or object in frontal space; hand or head moving in some direction to represent the trajectory of the referent; two hands or body mimicking an action), or which symbolises, by metaphor or metonymy, an abstract idea (e.g. hand or head movement towards the left or the right to symbolise the past or the future; gesture metaphors for abstract concepts).

\section{Non-representational gestures}

a. Performative: Gesture which allows the gestural realisation of a speech act (for instance, head nod as a yes answer, head shake as a no answer), or which co-expresses, together with the verbal utterance, the illocutionary value of a speech act (for instance, head nod accompanying a yes answer).

\footnotetext{
2 http://w3.u-grenoble3.fr/lidilem/labo/file/ANRMultimodalityresearchcodingmanual.pdf

Per Linguam 2015 31(3):1-18 
b. Framing: Gesture that expresses an emotional or mental state of the narrator (for instance, face showing amusement to express the comical side of an event; shoulder shrug or facial expression of doubt to express incertitude of what is being asserted).

c. Discursive: Gesture which aids in structuring speech and discourse by the accentuation or highlighting of certain linguistic units (for instance, beat gesture accompanying a certain word; repeated beats accompanying stressed syllables), or which marks discourse cohesion by linking clauses or discourse units (for instance, brief hand gesture or beat accompanying a connective; pointing gesture with an anaphoric function, e.g. pointing to a spot to refer to a character or an object previously referred to and assigned to this spot).

d. Interactive: Gesture accompanied by gaze towards the interlocutor to express that the speaker requires or verifies his attention, or shows that he has reached the end of his speech turn or his narrative, or towards the speaker to show his own attention (for instance, nodding head while interlocutor speaks).

e. Word searching gestures or 'Butterworths' (McNeill, 1992: 76): A hand gesture or facial expression, which indicates that the speaker is searching for a word or expression (for instance, frowning, staring above, and tapping of fingers while searching for words).

\section{Gesture - speech semantic relationship}

- The gesture-speech relation has proved a relevant issue in studying infant gestures during the transition to two-word speech (Butcher, 2000; Volterra, Caselli, Capirci \& Pizzuto, 2005). For instance, the production of certain gesture + word combinations (complementary or supplementary combinations) predicts the onset of syntax acquisition whereas other combinations (redundant combinations) do not. However, older children (6 years and older), and adults, have additional gesture-speech combinations (Colletta, 2004). The third stage of the coding consists in giving a definition of the relation of the gesture to corresponding speech, (Colletta et al. 2009: 60 for the coding convention). The coders had to choose between:

- Reinforcing gestures: The information brought by the gesture is identical to the linguistic information it co-occurs with (e.g. head nod accompanying a yes answer; face expressing ignorance while saying "I don't know"). This annotation does not concern the representational gestures, as the information brought by the representational gestures, always add more than the linguistic information, as per McNeill (1992); Kendon (2004); Colletta et al. (2009).

- Complementary gestures: The information provided by the gesture brings a necessary complement to the incomplete linguistic information provided by the verbal message: the gesture disambiguates the message, as in the case of deixis (e.g. pointing gesture accompanying a location adverb like " here », " there »; pointing gesture aiming at identifying an object not explicitly named). There 
were no complementary gesture-speech combinations as there were very few deictic gestures in the data.

- Supplementary gestures: The information brought by the gesture adds a supplementary signification to the linguistic information, like in the case of representational gestures ('jump' + a fist in the shape of an egg jumping) or framing gestures and certain performative gestures (e.g. vigorous shaking of head accompanying a no answer; face showing amusement signs to express a comical side of an event; shrugging or showing a mimic of doubt to express incertitude of what has been asserted). All framing gestures were coded as supplementary.

- Integration gestures: The information provided by the gesture does not add additional information to the verbal message, but serves to make it more precise, thanks to the imagistic properties of gesture ("the egg fell" + fist gesture in the shape of an egg moving on a certain trajectory and speed). Only representational gestures were coded to have an integration link to speech.

- Contradictory gestures: The information provided by the gesture is not only different from the linguistic information in which it is linked but contradicts it, as in the case of certain performative gestures (nodding the head while saying 'no') as in ironic expressions.

- Substitution gestures: The information provided by the gesture replaces linguistic information, as in the case of certain performative and interactive gestures (e.g. the speaker nods as a yes answer, shakes head as a no answer, shrugs to express his ignorance of the information required), such as emblems or quotable gestures (Kendon, 2004: 96). The few substitution gestures in the Zulu corpus corresponded to onomatopoeia ("the egg went [sound of egg falling + gesture]").

\section{RESULTS}

The transcribed data on ELAN were exported to Excel and SPSS for quantitative analyses. Statistical analysis was performed on the data with the One-way analysis of variance (one-way ANOVA) used to compare means of all the variables between the four age groups. The analysis of gender generally failed to reach significance, therefore, all subsequent statistical analyses were performed across both genders.

\section{Age effect on speech}

To determine the informational quantity of the narrative, the speech stream was segmented into different linguistic units, such as speech turns, clauses, words syntactic structures, macro-structural episodes of the narrative event to measure discursive ability in line with the stimulus presented to the speaker. Using Berman \& Slobin's (1994) definition, a 'clause' included a predicate matched by one or several arguments. The following were considered single clauses (example from a Zuluspeaking, 9-year-old boy and its corresponding morphemic English translation):

\section{Ngibone ipopayi 1s-see-past N5-cartoon.character past-sbj5-run loc-nest-loc I saw a cartoon character}

Per Linguam 2015 31(3):1-18

http://dx.doi.org/10.5785/31-3-560 


\section{2. .beligibele esidlekeni • past-sbj5-climb loc-nest-loc it had climbed on a nest}

\section{3. kuneqanda lapha phakathi" expl-have-N5-egg here inside ...there is an egg inside}

We observed the lowest means for the 5- to 6-year-olds' clauses, and the highest means for the 11- to 12-year-olds' clauses, with intermediate means for the adults' narratives.

\section{Table 1: Number of clauses}

\begin{tabular}{|c|c|}
\hline Age & Mean \# of clauses \\
\hline 5 to 6 years & 31.5 \\
\hline 9 to 10 years & 45.8 \\
\hline 11 to 12 years & 55.5 \\
\hline Adults & 48.9 \\
\hline
\end{tabular}

We observed a significant effect of age on the numbers of clauses $(F(3.42)=3.99, p<$ .01 ) and post-hoc test, Bonferroni, $\mathrm{p}<.05$ showed that the 5 - to 6-year-olds were not significantly different from the 9- to 10 -year-olds but were significantly different to the 11- to 12-year-olds. The 9- to 10-year-olds did not differ significantly from the 11- to 12-year-olds and adults. When looking at the means, we note that the 11- to 12year olds had a higher mean than the adults.

This result was similar to the finding from a study by Colletta et al. (2009). They suggest that a lower mean for adults is due to the ability of adults to summarise. The authors further postulated that children do not really understand the point of summarising stories until they reach the last two years of primary school (9 to 11 years of age) and have some difficulty summarising texts at secondary school. Younger children tend to give a detailed event-by-event retelling without using complex discourse clues, such as connectives or conjunctions to shorten their tale while including everything (Colletta et al., 2009; 2015).

\section{Effect of age on the pragmatic structure of clauses}

When analysing the discourse structure of our narrative data, we considered the pragmatic acts of the clauses, as described in the linguistic coding section of this paper. These were the acts of a) narration, b) explanation, c) interpretation and d) commenting, whilst recounting the story. These four categories were further grouped into narrative (narrative clauses) and non-narrative clauses (commentary, interpretation and explanation). The pragmatic act that had the highest appearance was the narrative clause at $90.2 \%$ of the total number of clauses across all ages (Table 2). 
Table 2: Mean number of pragmatic type of clause per age group

\begin{tabular}{|l|c|c|c|c|c|c|c|c|c|}
\hline Age group & \multicolumn{2}{|c|}{ Narrates } & \multicolumn{2}{c|}{ Comments } & \multicolumn{2}{c|}{ Interprets } & \multicolumn{2}{|c|}{ Explains } & Total \\
\hline & $\#$ & $\mathbf{\%}$ & $\#$ & $\mathbf{\%}$ & $\#$ & $\mathbf{\%}$ & $\#$ & $\mathbf{\%}$ & \\
\hline 5 to 6 yrs & 340 & 94.2 & 7 & 1.9 & 10.0 & 2.8 & 4.0 & 1.1 & 361 \\
\hline 9 to 10 yrs & 495 & 92.4 & 7 & 1.3 & 27.0 & 5.0 & 7.0 & 1.3 & 536 \\
\hline 11 to 12 yrs & 473 & 87.4 & 7 & 1.3 & 41.0 & 7.6 & 20.0 & 3.7 & 541 \\
\hline Adults & 477 & 82.8 & 31 & 5.4 & 57 & 9.9 & 11.0 & 1.9 & 576 \\
\hline Total & $\mathbf{1 7 8 5}$ & $\mathbf{8 8 . 6}$ & $\mathbf{5 2}$ & $\mathbf{2 . 6}$ & $\mathbf{1 3 5}$ & $\mathbf{6 . 7}$ & $\mathbf{4 2}$ & $\mathbf{2 . 1}$ & $\mathbf{2 0 1 4}$ \\
\hline
\end{tabular}

In the above table, we see a decrease of the narrative clause and an increase of the non-narrative clause with age. The adults produce only $82.8 \%$ of narrative clauses and the rest of the discourse is filled with non-narrative clauses (commentary, interpretation and explanation). We note that the youngest children stayed very much on the narrative level and barely used non-narrative clauses. This result was expected due to the nature of the task. In a previous study of spontaneous narratives, Colletta (2004: 220) found that children younger than 9 years of age were less likely to easily navigate between the narrative, meta-narrative and para-narrative levels. He hypothesised that there is a shift towards more complex discourse that is indicated by the increased use of the non-narrative clauses.

Adults produced a higher proportion of non-narrative clauses than the children. We then grouped the non-narrative clauses together (commentary, explanation and interpretation) to have a better view of the age-related effect on pragmatic clauses (see Table 3) and compared them to the narrative type of clauses.

Table 3 : Mean number of non-narrative and narrative clauses

\begin{tabular}{|l|c|c|}
\hline Age group & $\begin{array}{c}\text { Mean number of non-narrative } \\
\text { clauses } \\
\text { (SD) }\end{array}$ & $\begin{array}{c}\text { Mean number of } \\
\text { narrative clauses } \\
\text { (SD) }\end{array}$ \\
\hline 5 to 6 yrs & $1.50(1.7)$ & $28.58(6.57)$ \\
\hline 9 to 10 yrs & $3.25(3.1)$ & $41.42(5.40)$ \\
\hline 11 to 12 yrs & $4.30(4.3)$ & $50.0(1.90)$ \\
\hline Adults & $8.25(6.2)$ & $39.5(4.00)$ \\
\hline
\end{tabular}

The results from a between subjects ANOVA show a global significant effect of age on the number of non-narrative clauses $(\mathrm{F}(3.42)=5.67 \mathrm{p}<.002)$. The post-hoc test revealed that the 5 - to 6-year-olds produced a significant difference of $(p<.002)$ to the adults and the 9- to 10 -year-olds also had a significantly lower production of ( $\mathrm{p}<$ 0.32 ) to the adults.

As seen in Table 2, the adults produced fewer narrative clauses $(82.6 \%$ of total clauses) compared to the children groups, but they used more complex phrases to recount the narrative as they commented, interpreted and explained more than the children groups. This finding is consistent with previous research (Colletta et al. 2010). The complex pragmatic clauses are clearly demonstrated when regrouping the non-narrative clauses as in Table 3, where we can see that they increased with age; 
that is to say, adults had a higher proportion of non-narrative production than the children. Our results confirm the hypothesis of complex discourse being acquired late in child acquisition, as by the time the child begins primary school, discourse abilities are far from being achieved (Halliday \& Hasan, 1976; Fayol, 1997; Hickman, 2003; Colletta, 2004).

However, the overall means of the non-narrative clauses were quite small for even the adult group. Our findings in this particular task, which elicits oral narratives in a semi-experimental condition, do not provide sufficient evidence to allow us to hypothesise that, children younger than 10 years of age have not completely acquired the complex pragmatic structures that are used in storytelling. If the adults do not show a high frequency of non-narrative clauses, it is normal that the children will also display a developmentally proportional amount. In a related study on French narratives (Colletta et al., 2015), the adults produced a higher number of nonnarratives and in turn the children also produced a proportional high frequency even though a developmental trend was observed.

\section{Gesture results}

Individuals vary in their manner of speech and gesture. So to account for individual and age group differences, we did not use the mean numbers of gesture strokes, as there was a huge variation between the participants; some produced a few gesture strokes whilst other produced a high number of gesture strokes. To overcome this variation, we used a gesture ratio instead, by counting the number of gestures and dividing it by the number of clauses used per participant (Table 4). For further literature on the types of gesture ratios see Hostetter \& Alibali, (2007); Colletta et al. (2009).

Table 4: Mean number of clauses and gesture ratio per age group

\begin{tabular}{|llcc|}
\hline \multicolumn{1}{|c}{ Age group } & N & Mean number of clauses (SD) & $\begin{array}{c}\text { Mean gesture rate } \\
\text { (SD) }\end{array}$ \\
\hline 5 to 6 yrs & 12 & $31.5(7.2)$ & $0,3(0.3)$ \\
\hline 9 to 10 yrs & 12 & $45.8(6.3)$ & $0.5(0.3)$ \\
\hline 11 to 12 yrs & 10 & $55.5(4.0)$ & $0.8(0.4)$ \\
\hline Adults & 12 & $48.9(7.9)$ & $1.3(0.4)$ \\
\hline
\end{tabular}

The ANOVA on gesture ratio revealed an age effect between the four groups, ( $\mathrm{F}$ (3, $42)=18.61, p<.001)$. Post-hoc Bonferroni tests showed that the age effect concerned the difference between the 5- to 6-year-olds to the 11 - to 12 -year-olds $(\mathrm{p}<0.006)$ and to the adults $(\mathrm{p}<.001)$. The 11 - to 12 -year-olds and adults gestured far more than the 5 - to 6-year-olds. The adults showed a significant difference to all children groups $(\mathrm{p}$ $<0.01, \mathrm{p}<0.01$ and $\mathrm{p}<0.02$ respectively). The 5- to 6-year-olds and the 9- to $10-$ year-olds show no significant difference to each other in their gesture rate. There was also no significant difference between the 9- to 10- and the 11- to 12-year-olds. As can be seen in Figure 2, gesture rate increases with age. 
Figure 2: Gesture rate (\# of occurrences per clause) for each age group

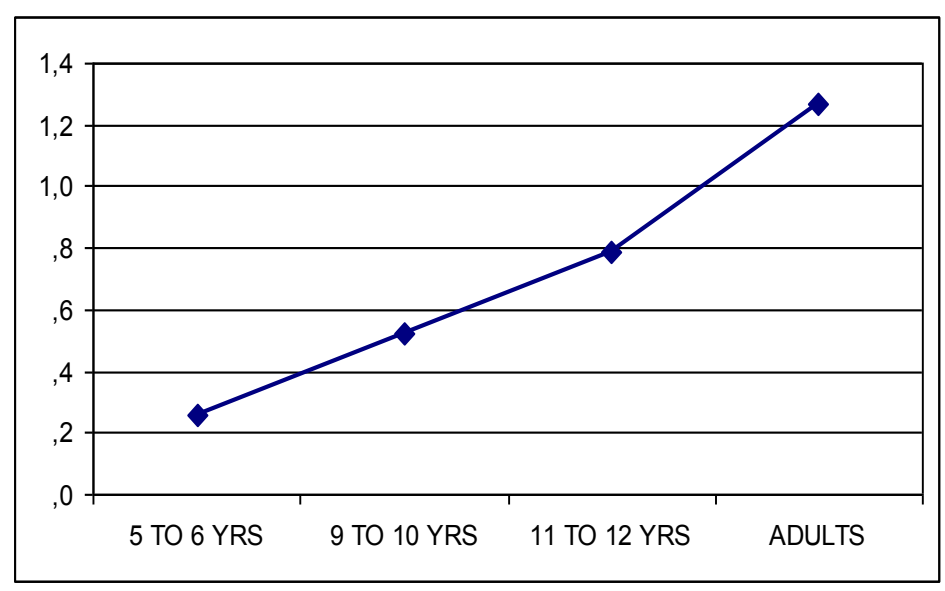

The net increase of the gesture rate shows that children increase their use of gesture per clause. A finding also confirmed by Graziano (2009) for Italian children and Colletta et al. (2010) for similar age groups.

\section{Gesture type}

There were no deictic gestures throughout the whole corpus. Of the type of gestures produced, the highest occurring gesture type was the representational gesture (Figure $3)$. This is normal due to the nature of the task of narrating. The infrequent occurrences of the performative gestures, as well as the low occurrence of the interactive gestures were due to the nature of the task being primarily monologic and not so much dialogic which would entail the continued participation of the interlocutor. The participants also did not have to perform speech acts, such as questioning, requesting, accepting, etc. as the task was on conveying narrative information. Performatives (nodding of the head, shaking of the head) were sparingly used at the end of the narrative. Nevertheless, discursive and framing gestures show a developmental tendency that we will analyse statistically.

\section{Figure 3: Mean gesture type}

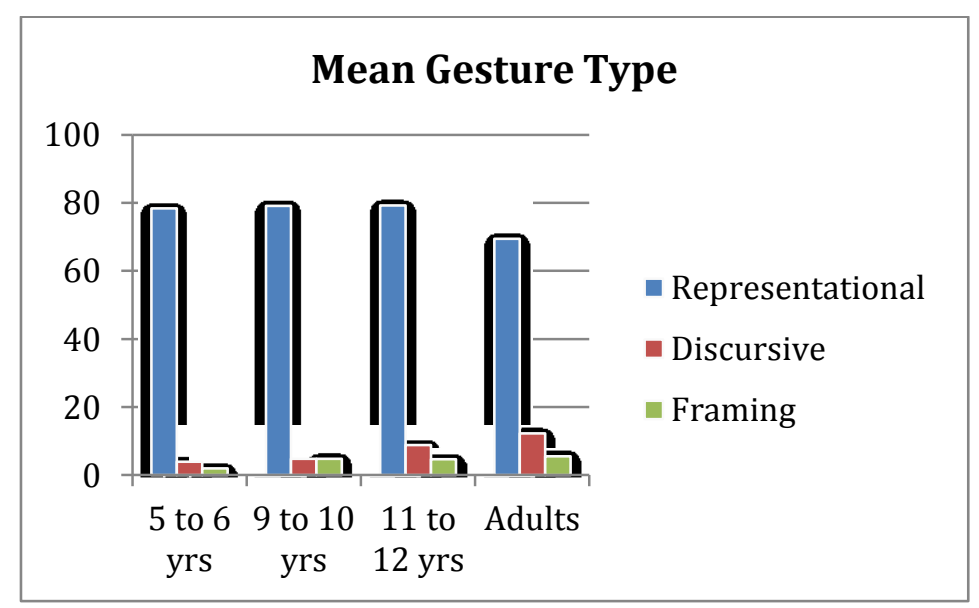


We performed a 2 X 2 ANOVA with age as a between-subjects factor. This revealed that there was an effect of age $(\mathrm{F}(3.42)=10.63, \mathrm{p}<.001)$ with the post-hoc Bonferroni tests $\mathrm{p}<.001$ and $\mathrm{p}<005$ showing that the age effect for the most frequent type of gesture (representational gestures) only concerned the difference between the 5- to 6- year-olds, the 11- to 12-year-olds and adults; the 9- to 10-yearolds showed a significant difference to the adults only. There was no significant difference between the 11- to 12-year-olds and the adults. Discursive gestures also showed an age effect as they increased with age. We found a significant effect of age between ALL the children groups and the adults $(\mathrm{F}(3.42)=12.55, \mathrm{p}<.001)$. The post-hoc test showed that the adults' use of the discursive gesture were significantly higher than all three children groups. The rate of the framing gesture also showed an age effect $(\mathrm{F}(3.42)=7.00, \mathrm{p}<.001)$. The post-hoc test showed that the 5- to 6-yearolds and the 9- to 10-year-olds produced significantly fewer framing gestures to the adults' $\mathrm{p}<.001$ and $\mathrm{p}<0.34$, respectively. There was no significant difference in the use of framing gestures between the adults and the 11- to 12-year-olds.

\section{Gesture-speech combination}

The gesture relationship to speech was coded as reinforcing, integrating, supplementing, contradicting, complementing or substituting speech. In our corpus, there were few or no gestures that were substituted or were contradictory to speech. As there were not deictic gestures, there were also no complementary gestures, which give the semantic function of deictic gestures. We therefore analysed the relationships that were more frequent: gestures that reinforced, integrated and supplemented the verbal message.

Figure 4: Mean gesture-speech semantic relationship

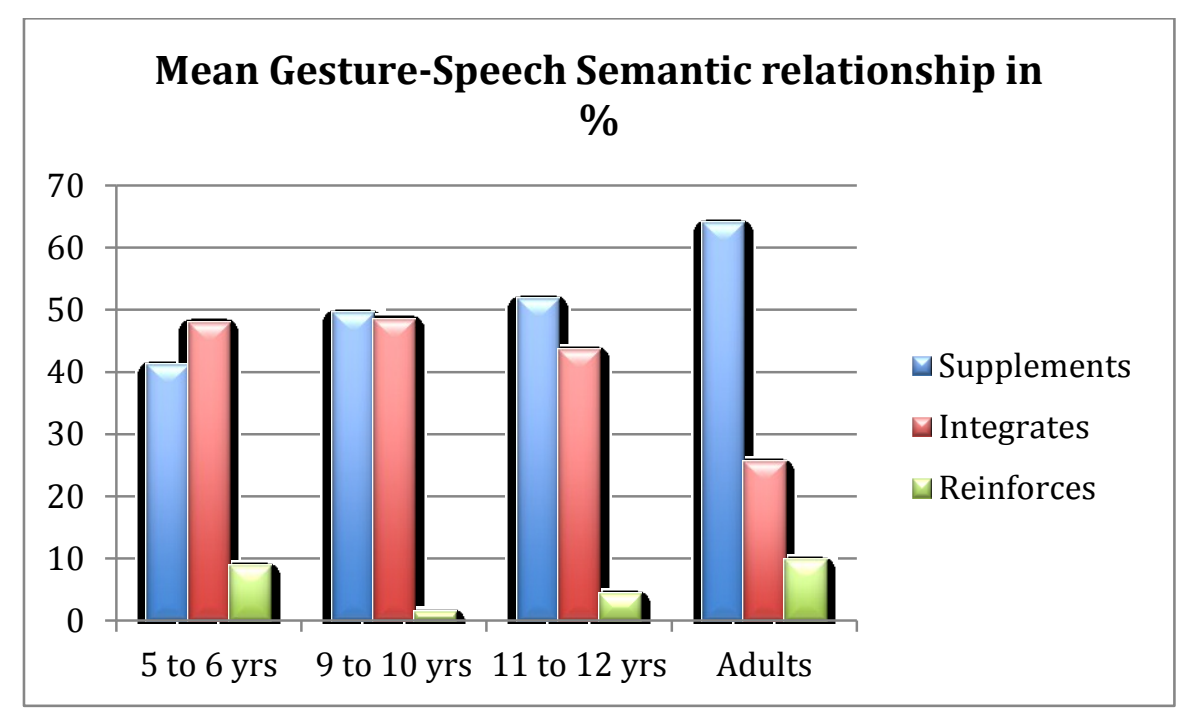

From Figure 4, the gesture-speech combination that is prevalent is that of supplementation, followed by integration and lastly, reinforcement of the verbal message. We then measured the gesture-speech rate of supplementary gestures, i.e. the gesture relation per clause. The ANOVA analysis showed an effect of age (F (3. 
$42)=23.53, p<.001)$ and the post-hoc Bonferroni test showed that it was significant for all the children groups to the adults. There was also a significant difference between 5- to 6-year-olds and the 11- to 12-year-olds $\mathrm{p}<0.027$. There was no significant difference between the 9- to 10- and the 11- to 12-year-olds. This result shows that most of the gestures in the data had a supplementary relationship to speech; they added additional information, and that it develops with age amongst Zulu children.

It is interesting to note that the younger children produced more integrating or redundant gestures, i.e. gestures that do not add additional information to speech, but serve to make it precise (McNeill, 1992; Colletta et al., 2009). We also note that the 5 - to 6-year-olds have a similar percentage of reinforcing gestures to the adults. As we do not observe a developmental shift in this gesture-speech combination, i.e. there is a random distribution over the age groups, we can speculate that this type of combination was not very essential in this narrative task.

\section{CONCLUSION AND DISCUSSION}

This study brings about evidence as to the complex nature of narrative discourse. Discourse develops with age, as found in literature on child development (Berman \& Slobin, 1994; Hickmann, 2003; Berman, 2008) and we see that children of 12 years do not perform the discursive activity as proficiently as adults. Adults are able to navigate between narrative and meta-narrative levels and children under the age of 12 years have yet to perform similarly. The adults had a higher number of non-narrative clauses (commentary, interpretation and explanation) than the children groups. The children remained predominantly on the narrative level. This complexity of navigating between the narrative, meta-narrative and para-narrative levels displays the complexity of the narrative (McNeill, 1992).

We also note a developmental trajectory between the children's groups with children of 12 years giving a more informational complex narrative than the 10-year-old children, who in turn, give a more informational complex narrative than a 5-year-old child in this language production task. Adults are able to give a more summarised or synthetic account using various discursive clues whereas the younger children tend to give a lengthy, event-by-event narration of what they had seen. This complexity of the oral narrative is viewed in both the speech level and the gestural level. With age, narrative information as measured by clauses increased and so did co-speech gesture.

We also note that the highest type of gesture in this task was the representational or iconic gesture. Whilst one would have expected to see less iconic gestural representations with the adults as seen in studies such as that of McNeill (1992) and Colletta et al. (2010), that show adults using more abstract and pragmatic gestures in their narrations and fewer iconic/concrete or representational gestures. Conversely, in the case of the Zulu adult speakers, we note that the adults produced a significantly higher number of representational gestures to the younger children groups. In a similar study for French speakers, Colletta et al (2010) found that adults produced fewer representational gestures than the children's groups and had an increased number of discursive or pragmatic gestures. For the Zulu speakers, we note that this is the opposite. The more information Zulu speakers recount in their tales, the more 
they want to give a visual performance. In a comparative study with Zulu and French (Kunene, 2010), it was observed that this may be due to a cultural particularity in Bantu languages which is linked to the nature of the task. For a Zulu speaker, who comes from a tradition of orature or African folktales, telling a story is a performance. The more information the speaker includes in the tale, the better the speaker.

We also note that this has a developmental trajectory with the adults producing more gestures with additional information than the child cohorts. The younger children produced a higher number of integration or redundant gestures to the speech message than the adults as they tried to give a concrete tale, faithful to exactly what they saw and recalled. The children showed that they were taking the character voice of their narrative, which could explain why they produced a higher proportion of gestures that emphasised their message, unlike the adults who used gesture to give additional information not expressed in speech.

\section{LIMITATIONS}

An in-depth exploration of the linguistic effects of gesture, such as is gesture used to compensate speech in the introduction, tracking and maintenance of referents would give us a better understanding of the discursive strategies used in a Zulu narrative. It would also be of interest to see how the narrative structure of Bantu languages compares to other languages, such as English and Afrikaans, which are languages of learning in South Africa. Experimental conditions come with limitations; the way people respond to data collection methods also has an effect on narrative and gesture production. A previous study on French spontaneous narratives produced by children aged six to eleven years (Colletta, 2009) showed advanced social abilities in the tenand eleven-year-olds that were not found in the children's narratives collected for these studies. Data collection methods may have effects on results in cross-linguistic and cross-cultural investigations and should be given more consideration. In order to further our understanding of multimodal development of oral narratives, it would be interesting for future studies to investigate if the speech and gestural behaviour is similar in a spontaneous oral task, say a child telling a story of their choice. It would also affect the results if the child would tell their tale to another child or someone they knew had not seen the tale. Would children's cognitive processing be heavier when telling their narration to someone who has not seen what they had seen?

In conclusion, gesture and speech show a tight link in communicative interactions. We also see this as they develop in parallel to speech and the milestones that children reach in speech. Co-speech gesture remains understudied and more lesser-known languages, such as Zulu, need to be investigated over and above the usual morphological study of the noun class system that is prevalent in linguistics. Understanding the underlying mental processes that drive the comprehension and production of extended discourse in children would enhance curricula planning, as the cognitive phases of the learner phase will be incorporated, giving precision to what is expected of a child in terms of literacy. 


\section{ACKNOWLEDGEMENTS}

The National Research Foundation (NRF) of South Africa under Grant 84343 supported the reporting of this work.

I would like to thank the participating primary schools, (Obanjeni; Gingindlovu and Akyalang). I also thank the students of the University of Zululand (Ongoye) for their willingness to participate in this study.

\section{REFERENCES}

ADLER, JM. 2012. Living into the story: agency and coherence in a longitudinal study of narrative identity development and mental health over the course of psychotherapy. Journal of Personality and Social Psychology 102(2): 367.

ALAMILLO, AR, JM COLLETTA \& M GUIDETTI. 2013. Gesture and language in narratives and explanations: the effects of age and communicative activity on late multimodal discourse development. Journal of Child Language 40(3): 511-538.

BEATTIE, G \& H SHOVELTON. 2006. When size really matters: How a single semantic feature is represented in speech and gesture modalities. Gesture 6: 63-84.

BERMAN, R. 2004. Language development across childhood and adolescence. Amsterdam: John Benjamins Publishing.

BERMAN, R. 2008. The psycholinguistics of developing text construction. Journal of Child Language 35: 735-771.

BERMAN, RA \& DI SLOBIN. 1994. Relating events in narrative: A Crosslinguistic developmental study. Psychology Press.

BRUNER, J. 1991. The narrative construction of reality. Critical inquiry 18: 1-21.

BUTCHER, C. 2000. 12 Gesture and the transition from one-to two-word speech: when hand and mouth come together. Language and Gesture 2: 235-258.

CAPIRICI, O, JM IVERSON, E PIZZUTO \& V VOLTERRA. 1996. Gestures and words during the transition to two-word speech. Journal of Child Language 23(3):645-673.

COLlETTA, JM. (2004) Le développement de la parole chez l'enfant âgé de 6 à 11 ans: corps, langage et cognition (Vol. 254). Editions Mardaga.

COLLETTA, JM, R KUNENE, A VENOUIL, V KAUFMANN \& J-P SIMON. 2009. Multi-track annotation of child language and gestures. In KIPP, M, J.C MARTIN, P PAGGIO \& D. HEYLEN (Eds.) Multimodal Corpora : From models of natural interaction to systems and applications 5509: 54-72. Berlin/Heidelberg: Springer, LNAI.

COLLETTA, JM, C PELLENQ \& M GUIDETTI. 2010. Age-related changes in cospeech gesture and narrative: Evidence from French children and adults. Speech \& Communication 52: 565-576.

COLLETTA, JM, M GUIDETTI, O CAPIRICI, C CRISTILLI, OE DEMIR, RN KUNENE-NICOLAS \& S LEVINE. 2015. Effects of age and language on co-speech gesture production: an investigation of French, American, and Italian children's narratives. Journal of Child Language 42(1): 122-145.

DEMUTH, K. 1992. Accessing functional categories in Sesotho: Interactions at the

Per Linguam 2015 31(3):1-18

http://dx.doi.org/10.5785/31-3-560 
morpho-syntax interface. In MEISEL, JM (Ed.) The Acquisition of Verb Placement. The Netherlands: De Kluwer Academic Publishers. pp. 83-107.

FAYOL, M. 1997. Des idées au texte: psychologie cognitive de la production verbale, orale et écrite. Paris : Presses Universitaires de France.

GARRETT, MF. 1982. Production of speech: Observations from normal and pathological language use. In ELLIS, A. (Ed.) Normality and pathology in cognitive functions. London: Academic Press. pp. 19-76.

GOLDIN-MEADOW, S. \& C BUTCHER. 2003. Pointing toward two-word speech in young children. In KITA, S (Ed.) Pointing: Where language, culture, and cognition meet. Hillsdale, NJ: Lawrence Erlbaum Associates. pp. 85-107.

GRAZIANO, M. 2009. 'Le développement de la relation entre les compétences verbale et gestuelle dans la construction d'un texte narratif chez l'enfant âgé de 4 à 10 ans'. Unpublished doctoral dissertation, Université Stendhal, Grenoble \& Universitadegli Studı Suor Orsola Benincasa, Naples.

GUIDETTI, ML. 2002. The emergence of pragmatics: forms and functions of conventional gestures in young French children. First Language 22: 265285.

GULLBERG, M, K DE BOT \& V VOLTERRA. 2010. Gestures and some key issues in the study of language development. Gestures in Language Development. Amsterdam: John Benjamins. 3-33.

HADLEY, PA \& CM SCHUELE. 1998. Facilitating Peer Interaction Socially Relevant Objectives for Preschool Language Intervention. American Journal of Speech-Language Pathology 7(4): 25-36.

HALLIDAY, MA \& R. HASAN. 1976. Cohesion in spoken and written English.

HICKMANN, M. 2003. Children's discourse: person, space and time across languages. Cambridge : Cambridge University Press.

HOSTETTER, AB. \& MW ALIBALI. 2007. Raise your hand if you're spatial: Relations between verbal and spatial skills and gesture production. Gesture. 7:73-95.

KENDON, A. 2004. Gesture: Visible action as utterance. Cambridge: Cambridge University Press.

KITA, S \& A ÖZYÜREK. 2003. What does cross-linguistic variation in semantic coordination of speech and gesture reveal? Evidence for an interface representation of spatial thinking and speaking. Journal of Memory and Language 48: 16-32.

LABOV, W. 1978. Denotational structure. In D FARKAS, W JACOBSEN \& K TODRYS (Eds.) Papers from the $14^{\text {th }}$ Annual Regional Meeting of the Chicago Linguistic Society: Parasession on the Lexicon. Chicago Linguistic Society. pp. 220-260.

LAFOREST, M. and D VINCENT. 1996. Du récit littéraire à la narration quotidienne. In LAFOREST M (Ed.), Autour de la narration. Québec » Nuit blanche pp. 13-28.

LEVELT, W. 1989. Speaking: From intention to articulation. Cambridge, MA: MIT Press.

MCCABE, A \& PR ROLLINS. 1994. Assessment of preschool narrative skills. American Journal of Speech-Language Pathology 3(1): 45-56.

MCNEILL, D. 1992. Hand and mind: What gestures reveal about thought. Chicago: University of Chicago Press.

MCNEILL, D. 2005. Gesture and thought. Chicago: University of Chicago Press.

Per Linguam 2015 31(3):1-18

http://dx.doi.org/10.5785/31-3-560 
MOONSAMY, S, H JORDAAN \& K GREENKOP. 2009. Cognitive processing and narrative discourse production in children with ADHD. South African Journal of Psychology 39: 326-335.

NORBURY, CF \& DV BISHOP. 2003. Narrative skills of children with communication impairments. International Journal of Language \& Communication Disorder 38: 287-313.

PETERSON, C. \& A MCCABE. 1991. Linking children's connective use and narrative macrostructure. In PETERSON C \& A MCCABE (Eds.) Developing narrative structure. Hillsdale NJ, Hove and London: Lawrence Erlbaum Associates. pp. 29-53.

STADLER, MA \& GC WARD. 2005. Supporting the narrative development of young children. Early Childhood Education Journal 33(2):73-80.

SUZMAN, S. 1991. Language acquisition in Zulu. Unpublished doctoral dissertation, University of the Witwatersrand.

VOLTERRA, V, MC CASELLI., O CAPIRCI, \& E PIZZUTO. 2005. Gesture and the emergence and development of language. In TOMASELLO $\mathrm{M} \& \mathrm{DI}$ SLOBIN (Eds.) Beyond nature-nurture: Essays in honour of Elizabeth Bates. Mahwah, NJ: Lawrence Erlbaum Associates. pp. 3-40.

VYGOTSKY, LS. 1962. Language and thought. Massachusetts Institute of Technology Press, Ontario, Canada.

\section{BIOGRAPHICAL NOTE}

Ramona Kunene-Nicolas is Lecturer of Linguistics and Head of Department at the University of the Witwatersrand. She joined Wits in 2012. She is the coordinator of the Psycholinguistics and Semantics courses at both undergraduate and graduate levels. Her areas of interest are first language acquisition, bilingualism, multimodality of speech, discourse analysis, gesture and speech. 